\section{OCCUPATION AND RELATIVE RISK OF CUTANEOUS MELANOMA: A 45-YEAR FOLLOW-UP STUDY OF 15 MILLION PEOPLE IN FIVE NORDIC COUNTRIES}

${ }^{1} \mathrm{JH}$ Alfonso, ${ }^{2} \mathrm{Jl}$ Martinsen, ${ }^{2,3,4,5} \mathrm{E}$ Weiderpass, ${ }^{6,7} \mathrm{E}$ Pukkala, ${ }^{8} \mathrm{E}$ Lynge, ${ }^{9} \mathrm{~L}$ Tryggvadottir, ${ }^{3} \mathrm{P}$ Sparén, ${ }^{2} \mathrm{~K}$ Kjaerheim. ${ }^{1}$ Dep. of Occupational Medicine and Epidemiology, National Institute of Occupational Health, Oslo, Norway; ${ }^{2}$ Cancer Registry of Norway, Oslo, Norway; ${ }^{3}$ Department of Medical Epidemiology and Biostatistics, Stockholm, Sweden; ${ }^{4}$ Department of Community Medicine, Faculty of Health Sciences, University of Tromso-Arctic University of Norway, Tromsø, Norway; ${ }^{5}$ Genetic Epidemiology Group, Helsinki, Finland; ${ }^{6}$ Finnish Cancer Registry, Institute for Statistical and Epidemiological Cancer Research, Helsinki, Finland; ${ }^{7}$ School of Health Sciences, University of Tampere, Tampere, Finland; 'Department of Public Health, University of Copenhagen, Copenhagen, Denmark; ${ }^{9} /$ celandic Cancer Registry, Icelandic Cancer Society, Faculty of Medicine, University of Iceland, Reykjavik, Iceland

\subsection{6/oemed-2018-ICOHabstracts.1122}

Background The age-adjusted incidence of cutaneous melanoma (CM) in the Nordic countries has increased during the last 60 years. In Europe, the legislation of five out of 11 surveyed countries acknowledges $\mathrm{CM}$ as an occupational disease (Ulrich, et al, 2016). To our knowledge, population-based studies with a prospective design have not yet described the variation in the relative risk of $\mathrm{CM}$ among different occupational categories.

Aim 1. To describe the variation in the relative risk of $\mathrm{CM}$ according to occupational categories with outdoor, mixed, and indoor work, as well as socioeconomic status (SES).

2. To evaluate trends across periods.

Methods Historical prospective cohort study based on record linkages between census data for 15 million people and cancer registry data from 1961 to 2005 (Nordic Occupational Cancer Project, http://astra.cancer.fi/NOCCA). Standardised incidence ratios (SIR) were estimated for 53 occupational categories classified according to indoor, outdoor and mixed work and socioeconomic status.

Results During follow-up of 385 million person-years, there were 83898 incident cases of CM.

Statistically significant SIRs of CM were found among occupational categories with indoor work for male workers (1.09) and the highest socio-economic status for men (1.36) and women (1.31). Occupational categories with outdoor work for both men (0.79) and women (0.92), and the lowest socio-economic status showed lowest SIRs for both sexes (men: 0.69, women: 0.97). The SIR pattern was similar in all periods for occupational categories with outdoor, mixed and indoor work. Findings were consistent between the different Nordic countries.

Conclusion This historical prospective cohort study provides evidence of an increased relative risk of $\mathrm{CM}$ amongst occupational categories with indoor work for men, and highest SES for both sexes.

\section{CANCER INCIDENCE AMONG TANKER CREWS IN A COHORT STUDY OF SWEDISH SEAFARERS}

${ }^{1} \mathrm{E}$ Andersson*, ${ }^{2,3} \mathrm{~K}$ Forsell, ${ }^{4} \mathrm{O}$ Björ, ${ }^{1} \mathrm{R}$ Nilsson. ${ }^{1}$ Occupational and Environmental Medicine, Sahlgrenska University Hospital, Göteborg, Sweden; 'Occupational and Environmental Medicine, Sahlgrenska Academy, Gothenburg University, Sweden; ${ }^{3}$ Occupational and Environmental Medicine, Umeå University Hospital, Umeå, Sweden; ${ }^{4}$ Regional Cancer Centre North, Umeå University Hospital, Umeå, Sweden

10.1136/oemed-2018-ICOHabstracts.1123

Introduction Increased rates of leukaemia have been found among tanker crews. Exposure to benzene could be a cause since many products transported on tankers contain benzene. In a cohort of seafarers we studied cancer incidence among tanker crews.

Methods All persons in the Swedish Registry of Seafarers 1985-2011 with registered work periods were included in the total cohort $(n=75745)$ and followed up for cancer incidence from 1985 or first work period to emigration, cancer or 2011. A sub-cohort of tanker crews $(n=14596$ with at least one month on tankers) were used for this study. Standardised incidence ratio (SIR) were analysed with 95\% confidence intervals (CI) in relation to the Swedish population.

Result Total cancer risk for tanker crews was SIR 1.07 (cases $\mathrm{n}=1006$, 95\% CI: 1.01 to 1.14 ). The risk for lung cancer and leukaemia was increased, SIR $1.86(\mathrm{n}=127,95 \%$ CI: 1.54 to 2.19$)$ and SIR $1.40(\mathrm{n}=43,95 \% \mathrm{CI}$ : 1.01 to 1.82$)$, respectively. The risk for lymphoma and multiple myeloma was not increased. Most (90\%) of the crew members were men. There was a trend to normalised cancer incidence with time, analysing first employment before 1985, 1985 to 1991 and after 1991, significant for lung cancer $(\mathrm{p}=0.03)$. In the total cohort the risk for lung cancer was SIR 1.52 (95\% $1.37-1.66)$ and for leukaemia SIR 0.94 (95\% 0.78-1.11).

Discussion Seafarers working on tankers had an increased risk for leukaemia, which other seafarers did not have. Measurements on product tankers have shown that the deck crew could be exposed to rather high concentrations of benzene, especially during loading, unloading and tank cleaning operations. During the last decades, benzene exposure on tankers has presumably decreased (lower benzene content in gasoline, modern shipping with closed loading and unloading of tankers), possibly also resulting in decreased leukaemia incidence.

\section{REVIEW OF SICK LEAVE REFERRALS IN THE IRISH CIVIL SERVICE 2014-2016}

${ }^{1}$ A Jones*, ${ }^{2} \mathrm{~T} \mathrm{O}^{\prime}$ Connell. ${ }^{1}$ Specialist Registrar in Occupational Medicine, Civil Service Occupational Health Department, Dublin, Ireland; ${ }^{2}$ Chief Medical Officer, Civil Service Occupational Health Department, Dublin, Ireland

\subsection{6/oemed-2018-ICOHabstracts.1124}

Introduction Long-term sickness absence can have negative consequences for individuals, their employers and the organisations that they are working in. In such cases occupational health has an important role in assisting workplace rehabilitation. This study investigates long-term sickness absence referrals in the Irish Civil Service in terms of epidemiological profile, illness categories and eventual outcomes.

Methods A retrospective review was carried out of consecutive new long-term sickness absence cases referred between April and June 2014 inclusive. Cases were followed up for 2 years. Case outcomes were established by reviewing both electronic and paper records, and liaising with the relevant human resources department where necessary.

Results Two hundred and fifty two cases were available for analysis. Referral for long-term sickness absence was more common among older employees and female employees. Clerical Officer grades accounted for over one third of all referrals.

The principal diagnostic groups were mental health issues $(25 \%)$ and musculoskeletal disorders (20.6\%). The category that followed, accounting for $11.9 \%$ of all illnesses was 'physical other'. This category was comprised of a wide range of illnesses that were not elsewhere categorised. Cancer and 